\title{
SOCIOLOGICAL AND PSYCHOLOGICAL FACTORS IN VENEREAL DISEASE
}

\author{
By A. FESSLER, M.R.C.S., L.R.C.P., M.D. (Vienna) \\ Venereal Diseases Officer, Lancashire County Council
}

During World War II, the Lancashire County Council opened three venereal diseases clinics, one in Chorley (in April 1941), one in Lancaster (in May 1944) and one in Fleetwood (in November 1944). The following analysis is based on data collected from the reports of 200 consecutive civil patients who, during the period from 1st May 1943 to 30th May 1945, were treated for acute gonorrhoea or for early syphilis at these clinics. Cases which were transferred from other clinics have not been included.

\section{The social background}

The recent war accentuated the differences which existed in the economic structure of the districts served by the clinics. Chorley became the centre of an industrial area and saw the influx of a large number of female warworkers. Lancaster, despite some added industries, kept its character as one of the main commercial towns in northern Lancashire. The clinic there also serves the seaside resort, Morecambe, as well as a large rural area which includes the southern parts of Westmorland. The employment of a considerable number of sailors of the Allied Nations was a wartime feature of Fleetwood. The billeting of members of the British and of the Allied Forces in the Chorley and Lancaster districts had an important influence on the incidence of venereal disease in these areas.

Although certain trends of sexual morality-for example, the increased incidence of venereal diseases among married people-were discernible everywhere, the above-mentioned differences in the social and economic structure of the district were reflected clearly in the types of patient seen at each of the three clinics. In Chorley and in Lancaster female patients predominated, in Fleetwood male patients. The most common type of patient seen in Chorley was the young factory girl and in Lancaster the married woman. Nearly all the male patients seen in Fleetwood were sailors. Fleetwood, being mainly a fishing port, has not much ocean-going traffic, and therefore (in contrast with the experience at other ports) no infection has been reported there which had been acquired abroad. The three types of patient showed a correspondingly varying attitude towards their infection, which was manifested in various ways, for example in the regularity of attendances, in the cooperation given in tracing contacts and especially in the defaulter rate. The unfortunately high defaulter rate among the young factory girls contrasts strikingly with the regular attendance of the married women, especially those who had been infected by their husbands. There were exceptions, naturally, in both groups; there were some factory girls who regarded their infection seriously and some married women who, in spite of all our efforts, stopped treatment before they were cured. Nearly all the latter were infected extramaritally and their venereal infection has to be regarded as another sad sign of a disrupted family and a broken home.

Because the number of patients seen at each of the three clinics is relatively small, it seems to be inadvisable to treat their records separately. Furthermore, it is thought that, taken together from the three clinics, the patients form a good cross section of the population of the Lancashire county area, representing industrial and non-industrial urban districts, ports and seaside places, and rural areas. Nevertheless the conclusions drawn from this analysis cannot be generalized without reservations.

By comparing these data with similar information collected in other parts of the country, it might be possible to find certain common trends of the sexual morality of the present time. The study of the influence of social factors on the incidence of venereal dis

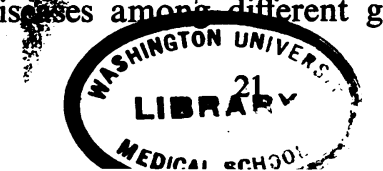




\section{THE BRITISH JOURNAL OF VENEREAL DISEASES}

provide useful information for the campaign against venereal disease, be it of a legislative or of an educational character.

\section{Sex incidence}

Grouped according to the incidence in male and female patients, our case records show the following results.

\begin{tabular}{|c|c|c|c|c|c|}
\hline $\begin{array}{l}\text { Syphilis } \\
\text { Gonorrhoea }\end{array}$ & $\begin{array}{l}\cdots \\
\cdots\end{array}$ & $\begin{array}{l}\cdots \\
\ldots\end{array}$ & $\begin{array}{c}\text { Males } \\
18 \\
63\end{array}$ & $\begin{array}{c}\text { Females } \\
38 \\
81\end{array}$ & $\begin{array}{c}\text { Total } \\
56^{*} \\
144\end{array}$ \\
\hline & & & 81 & 119 & 200 \\
\hline
\end{tabular}

In 1938 the ratio of male patients to female patients attending the venereal diseases clinics in England and Wales was $3: 2$ for syphilis and $4: 1$ for gonorrhoea (Ministry of Health $^{\mathbf{1}}$ ). The number of female patients has increased steadily since promiscuity replaced prostitution as the main source of infection. The present large percentage of female patients seen at the venereal diseases clinics for civilians is partly a result of the anti-venereal-disease campaign and partly a result of wartime conditions.

The ratio between gonorrhoea and syphilis for England and Wales during 1938 was $8: 1$ (Ministry of Health ${ }^{1}$ ). Quite early in the recent war it was realized that syphilis showed relatively a much larger increase than did gonorrhoea (Harrison $^{1}$ ) and it was repeatedly pointed out that the sulphonamide treatment of gonorrhoea was the cause of it. It is likely that penicillin treatment will alter the ratio again. The ratio among our patients-2.6:1-is nearer to the ratio given by Ross in 1944 for Liverpool, which was $3 \cdot 25: 1$.

Statistically there are no significant differences between the patients with gonorrhoea and those with syphilis; therefore in the remaining statistics all the patients are grouped together.

\section{Marital status}

Grouped according to whether the patients were married or single, our. records show the following figures.

\begin{tabular}{|c|c|c|c|c|c|}
\hline $\begin{array}{l}\text { Married } \\
\text { Single .... }\end{array}$ & $\begin{array}{c}\cdots \\
\cdots\end{array}$ & $\begin{array}{l}\ldots \\
\ldots\end{array}$ & $\begin{array}{c}\text { Males } \\
44 \\
37^{*}\end{array}$ & $\begin{array}{c}\text { Females } \\
69 \\
50^{*}\end{array}$ & $\begin{array}{c}\text { Total } \\
113 \\
87^{*}\end{array}$ \\
\hline & & & 81 & 119 & 200 \\
\hline
\end{tabular}

More than half of the number of patients were married. Similar observations about the high rate of incidence of venereal diseases among married people have been made in other parts of the country. Ross stated that of 100 female patients attending the Venereal Diseases Clinic at the Royal Infirmary in Liverpool, 71 were married. Of the 169 women contacts mentioned in the report of the Tyneside Experimental Scheme in Venereal Disease Control, 72 were married. Sexual morality in the United States of America seems to show the same trend. Rachlin reports that of 304 female patients with venereal diseases admitted to the Midwestern Medical Centre in St. Louis, 198 were married. There can be no doubt that the great increase of venereal disease among married people is, from the medical and moral points of view, one of the most serious consequences of the general wartime increase.

\section{Age groups}

The largest section of the patients-numbering 94 (47 per cent)-was of men and women between 21 and 30 years. This age group is also represented by the majority of the female patients mentioned in the Tyneside report, the pro- 


\section{SOCIOOGICAL FACTORS IN VENEREAL DISEASES}

portion in that case being 54 per cent. Our numbers are not large enough to permit of a detailed statistical study of the age groups of the-two sexes, but it is interesting to note that 15 of the female patients (about 12 per cent) were under 21 years of age, as compared with 5 (6 per cent) of the male patients.

Our records show the following distribution.

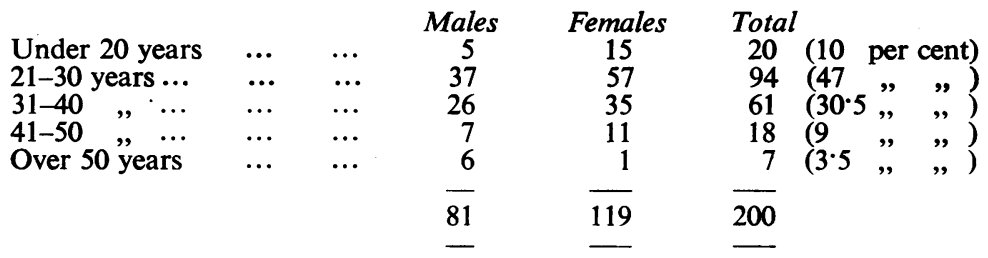

Motives for coming to the clinic

Among our 200 patients the motives for coming to the clinic have been analysed, with the following results.

Of the 81 male patients,

46 came of their own accord,

32 were sent by a general practitioner,

3 came after persuasion.

Of the 119 female patients,

16 came of their own accord,

48 were sent by a general practitioner,

21 came after being informed by letter from a military hospital that their husbands (or other male partners) were receiving treatment for venereal disease,

15 came after persuasion,

19 came after being informed by the Venereal Diseases Almoner that they had been notified under Regulation 33B ; 7 had been notified twice.

Psychologically it is interesting to note that 46 (57 per cent) of the male patients came of their own accord compared with 16 (13 per cent) of the female patients. It seems that the campaign against venereal disease is more effective among men than among women. It might, however, be easier for a man than for a woman to overcome the reluctance to seek advice at a venereal diseases clinic.

Of the male patients, 48 (40 per cent)-and approximately the same percentage of the female patients-came to the clinic after they had first seen a private doctor. This figure shows the important part which the general practitioners have to play in the campaign against venereal diseases. This fact has been stressed recently by Shiels.

Harrison $^{2}$ deals with the different methods of inducing contacts to come for treatment and favours most the method "through the original patient's effort"' Ross is of the same opinion. Among our 200 patients, 18 came to the clinic after persuasion, the persuasion being usually a combined effort of the partner and the Venereal Diseases Almoner. The difference in the number of males and females in this group-3 compared with 15 -is due to the fact that male patients are much more cooperative in tracing contacts than are females, provided that they are able to give any information. The social workers of the Tyneside Scheme had the same experience. Of our female patients, 21 came to the clinic after being advised by letter from a military hospital to do so. This figure shows how much the present venereal diseases scheme in the Forces is contributing to the general campaign. Of these 21 patients, 17 were married; 15 had syphilis and 6 had gonorrhoea. Nineteen of the female patients were contacts named under Regulation 33B ; 14 of these patients had gonorrhoea and 5 had syphilis. According to our experience, each method of bringing patients to the clinic has its own merits as well as its limitations and all deserve to be used.

\section{Sources of infection}

The question about the source of the infection was put to the patient in a casual manner, usually by pointing out how important it is to bring as many contacts 


\section{THE BRITISH JOURNAL OF VENEREAL DISEASES}

as possible for examination. The answers given were accepted without any further questioning, and it must be assumed that some of them were inaccurate. Of the 81 male patients, 58 attributed their infection to a casual acquaintance, such as a " pick-up " girl. In view of the fact that there is no definite borderline between promiscuity and prostitution in its various types, no request for further details was made.

Of the male patients, 15 stated that they had been infected by their wives and 6 by their " girl friends". Only one man answered that he did not know by whom he had been infected. One married man had an extragenital syphilitic chancre on his chin.

Of the 119 female patients, 31 answered that they did not know by whom they were infected, 39 stated that they were infected by a casual acquaintance and 16 by their " boy friends". Of the 69 married women, 32 accused their husbands. One girl had an extragenital syphilitic chancre on the chin.

As was to be expected, promiscuity proved to be the main source of infections. The scanty knowledge which the promiscuous man and woman have about their partners hinders to a very great extent all efforts to trace contacts.

\section{Occupation}

Grouped according to the patient's occupation, our records are as under.

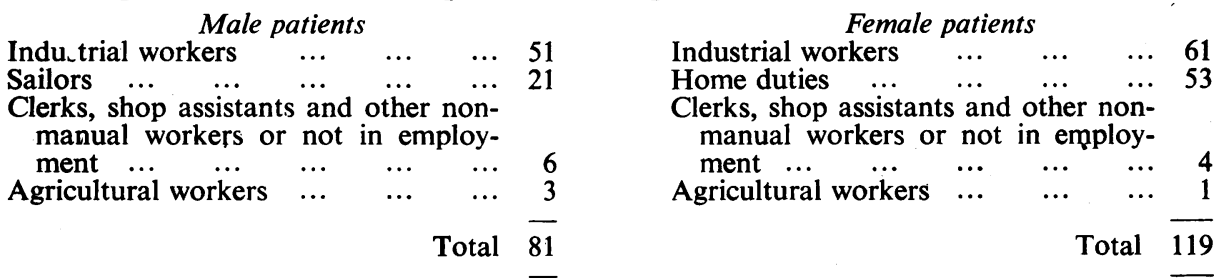

Nearly all the patients who attended our clinics belonged to the working class. The small number of agricultural workers is remarkable. Reports from the general practitioners who work under the domiciliary scheme have confirmed the impression that venereal diseases are not very common in areas with a predominantly agricultural population.

Patients belonging to the middle classes apparently prefer private treatment. It is therefore not possible to ascertain exactly to what extent the various classes of society have been affected by the wartime increase of the venereal diseases. Observations on the Continent (Fessler $\left.{ }^{2}\right)$ have shown that the reduction in the incidence of venereal diseases after World War I was much more marked among the middle classes. It might therefore be permissible to assume that the present increase of venereal disease is, indeed, as it seems to be, much higher among working-class people than in other classes of society. The lower incidence of venereal diseases among the middle classes might be explained by the fact that people who belong to these classes are, as a rule-because of the higher standard of their education-more careful in the choice of their partners and use preventive measures more frequently. If they acquire an infection, they appreciate its seriousness and possible consequences and do not default from treatment. If the incidence of venereal diseases is, in fact, higher among the less educated classes, it may be necessary to use a type of propaganda which they more easily understand.

\section{Defaulter rate}

A patient who had not attended for 2 weeks was regarded as a defaulter and the Venereal Diseases Almoner was asked to pay a home visit. For purposes of tabulation the defaulters were divided into 2 groups. (1) The first group comprised patients with gonorrhoea who defaulted before they had finished the actual treatment, together with patients with syphilis who defaulted before they had finished the first course of the intermittent-concurrent treatment. (This treatment was used exclusively.) (2) To the second group belonged patients with gonorrhoea who defaulted before all tests ( 4 in male cases and 5 in female) were concluded, 


\section{SOCIOLOGICAL FACTORS IN VENEREAL DISEASE}

and patients with syphilis who either did not begin the second course or defaulted at a later stage.

Of the 81 male patients 7 , and of the 119 female patients 8 cases were transferred to other clinics. Of the remaining 74 male patients, 47 attended regularly. Of the 27 defaulters 7 belonged to the first and 20 to the second group. One patient of the first and 11 patients of the second group reattended after being visited. Of the 15 patients who did not resume treatment, 7 were sailors.

Of the 111 female patients who remained in our care, 56 attended regularly. Of the 55 defaulters, 14 belonged to the first group, and 3 of them reattended. Of the 41 belonging to the second group, 28 resumed treatment.

Altogether there were 39 patients out of the 185 who defaulted permanently, 15 of whom were males and 21 were females. The percentage is approximately the same for both sexes, namely 20.

These figures show that, even without compulsory treatment, the defaulter rate can be considerably reduced, provided that the help of an experienced almoner is available. Although all apparent obstacles (including difficulties in getting " time off" from work, troubles with the family and other personal problems) were removed, some of the patients defaulted again and the home visits had to be repeated. Of the 39 persistent defaulters about 20 had left the district and could not be traced ; 18 of these 39 patients had syphilis and 21 had gonorrhoea.

\section{Discussion}

\section{Legislation on venereal disease}

The increase of venereal diseases during World War I led to a widespread demand for legislation. Consequently, Great Britain and many other countries overhauled already existing legislative measures or brought an entirely new scheme into being. Although all those legislative measures had the same aim, they varied greatly, according to the differences in the general attitude of the population in the various countries towards the venereal disease problem.

Great hopes were placed in some of the countries on notification and on compulsory treatment. The results achieved with these measures were not very satisfactory. The German enactment of October 1927, which provided confidential notification and compulsory treatment for defaulters, serves as a typical example of a failure. The causes of failure were lack of cooperation by the medical profession, the local authorities and the public, together with lack of money to provide the necessary staff for the complicated administration and lack of facilities for compulsory treatment. The economic crisis in the early nineteenthirties increased these financial difficulties, and the fate of the whole statutory scheme was doomed as soon as it became an issue between the political parties. Even in Sweden, however, in which country the legislation regarding venereal disease is usually quoted as exemplary, and in which all the necessary conditionscooperation, financial resources and a high general standard of education-are fulfilled, wartime conditions were again the cause of an increase in venereal disease (Hallgren). Even before the recent war, however, the Royal Commission of 1938, after studying measures taken against venereal disease in the Scandinavian countries and in Holland, came to the conclusion " that compulsory treatment does not seem to us to be a major factor influencing the results of the anti-venereal measures in the countries where it is employed"'.

The permanent value of the laws against venereal disease, passed during World War I and in the subsequent years, lies in the fact that it was for the first time generally realized that both sexes must be held to be equally responsible for the spread of infection. Nearly all countries abolished the obsolete and unjust methods of state regulation of vice and thus followed the lead given by Great Britain as early as 1886. The fact that Italy in 1931 and Germany after 1933 reintroduced state regulation, proves the close connexion which exists between the form of government of a country and its legislation on social hygiene (Fessler ${ }^{1}$ ).

The increase of venereal disease since the beginning of World War II has again produced in Great Britain a demand for stricter legislative measures (Laird ${ }^{1}$ and 2 ; Medical Advisory Committee for Scotland; Gordon). In 1942 Regulation 33B came into power. 


\section{THE BRITISH JOURNAL OF VENEREAL DISEASES}

Comparison of the venereal diseases literature published during the two world wars shows clearly that in the second period less confidence is placed in legislation alone. Education and propaganda are not only stated as being necessary, but are carried out to an extent not conceivable twenty years ago (Jameson).

\section{The social factor}

The greatest difference, however, lies in the fact that for the first time the importance of the social factors in the venereal disease problem is generally acknowledged. This fact undoubtedly reflects the general trend in Medicine which brought social medicine to the fore. It is interesting to note that it took so long a time for the importance of the social background of the venereal diseases to be fully realized. For' centuries it had been known that social changes, following on political or economic disturbances, influenced the incidence of venereal diseases much more than that of any other group of infectious diseases. Moreover, it is a well known fact that persons in certain occupations are specially exposed to the risk of a venereal infection. Whole groups-sailors, for example-present peculiar difficulties in the provision of complete treatment. The social aspects of venereal disease are mentioned only a few times in the literature of World War I. The Royal Commission on Venereal Diseases in 1916 stated in its general conclusions that " social conditions such as overcrowding and insanitary dwellings contribute to the spread of venereal diseases".

\section{The social worker in the venereal diseases clinic}

To take another early example of social insight, Osler, in 1917, mentioned the need for the employment of social workers at venereal diseases clinics. Some years later, White, in an article which seems to have been written far in advance of its time, opposes legislation which does not take into account the social and emotional sides of the venereal disease problem. After 1918, Holland and Russia seem to have been the first countries to make use of the social worker in the campaign against venereal disease. A few venereal diseases clinics in London appointed social workers and this example was followed very slowly in the provinces. The work to be done in this respect was outlined by Manchée for the first time in 1938. The increase of venereal diseases during World War II made it necessary to use all available methods for the campaign against them and, in consequence, more and more use was made of social workers. Burn reported on the good results of the home visiting of defaulters in Salford. The Ministry of Health ${ }^{2}$, in July 1943, asked the local authorities to appoint venereal diseases almoners in connexion with the work to be done under Regulation 33B. Gordon, who demands an " epidemiological approach" to the venereal disease problem, mentions the valuable work done by American nurses in this country in contact tracing. A team of social workers, supported by the Ministry of Health, was engaged in the Tyneside Scheme, and its members had the opportunity of studying the social background of promiscuity in women. At a meeting of the Medical Society for the Study of Venereal Diseases in 1944, the social aspects of venereal disease were discussed and it was unanimously agreed that the social worker had become an indispensable member of the staff of the venereal diseases clinic.

\section{The defaulter : a social and psychological problem}

Our own figures, small as they may be, show that with the help of a social worker a number of contacts can be traced by using the available methods, and that the defaulter rate can be reduced considerably. The fact remains, however, that certain persons who have acquired a venereal disease infection do not come for treatment despite all propaganda and that, if they are brought to the clinic, they sooner or later default and that all means of persuasion ultimately fail. It is for this type of uncooperative patient that compulsory treatment is so often demanded. For the time being, however, no satisfactory solution of the problems which beset compulsory treatment has been found. The medical aspect of treatment presents many problems, including the difficulty of diagnosing gonorrhoea in the female, 
the possibility of a clinical relapse after an apparent cure and the difficulties of distinguishing between relapse and reinfection. The supporters of compulsory treatment have so far not clearly stated where this type of treatment should be carried out. The old Lock Hospital type of institution, which provided treatment for prostitutes only, has fortunately died out. In the general hospitals there are not sufficient beds available for the in-patient treatment of venereal diseases, even without the introduction of compulsory treatment. To send defaulters to prison, for punishment as well as for treatment, cannot be regarded as a suitable solution of the problem. An interesting experiment has been made in the United States of America by admitting patients on a voluntary basis, as well as on a compulsory basis, to the so-called " special treatment centres " in which the new rapid methods are widely used.

It might be possible to find a new way to deal with the problem of the uncooperative venereal disease patient by approaching it from the psychological side. Since the time of Lombroso, numerous studies of the psychology of professional prostitutes have been made, which have established that the driving force is not exclusively-as it had been generally assumed-of economic origin, but is the result of an abnormal mentality.

Until recently the psychological background of promiscuity had not been examined.

Rachlin tested the intelligence of 293 female patients at the Midwestern Centre in St. Louis, using the Otis Beta B group test and the Stanford-Binet (Terman-Merrill revised) individual test. This investigator found that the average intelligence quotient of the patients was far below normal. For example, the 93 women who were examined with the Stanford-Binet test had an average mental age of 11 years and 3 months.

A similar result was obtained among men by Wittkower and Cowan in their clinical assessment of 200 soldiers treated for a venereal infection acquired extramaritally. A much higher percentage of immature personalities was found among them than among the 86 control cases (skin cases). Wittkower and Cowan also found among the venereal diseases patients a much higher percentage of overaggressive and of unaggressive dependent types, also a higher percentage of heavy drinkers and of criminals, than among the control cases.

Abel and Kinder published in 1942 a detailed'sociological and psychological study of the subnormal adolescent girl whose intelligence quotient is between 50 and 90 . (The intelligence quotient of the average normal adolescent girl is between 90 and 110 and of the mental defective girl below 50.) The subnormal girl may be dull and a moron or may be goodlooking and easygoing. Her main characteristics are an immature personality, lack of selfcontrol, emotional unstability, and the inability to understand the seriousness of a given situation and its possible consequences. Her subnormal mentality may remain undiscovered for a long time and becomes apparent only when the girl finds herself in trouble of some sort ; very often the trouble is of the pattern of sex delinquency. Abel and Kinder deal mainly with the adolescent girl, but they state that the same sort of mental subnormality can often be found, too, in the older age groups.

The description given of the subnormal girl fits very well the majority of female defaulters who are encountered at a venereal diseases clinic. According to our experience, this type of mental subnormality is relatively rare among the male defaulters; the reckless and the criminal types are more prevalent among them. However much one may agree that both sexes should be held equally responsible for the spread of venereal disease, one cannot escape that fact that, for physiological and psychological reasons, the problem of defaulting is greater among women than among men.

Defaulters are regarded usually as persons with antisocial tendencies. It seems that in the majority of cases these antisocial tendencies are the outcome of a subnormal mentality. As general experience has shown, little can be expected from the imposition of a fine or even from imprisonment. It is suggested, therefore, that we should approach the problem of the defaulter-or, to use a wider term, the problem of the uncooperative venereal disease patient-psychologically. If, by the use of the standard tests, the intelligence quotient of the uncooperative patient is found to be below normal, she or he should be admitted on certification to an institution. Such an institution should be neither a prison nor simply the venereal diseases ward in a hospital. It should be a place where the venereal infection is treated and, in addition, an attempt is made simultaneously at 


\section{THE BRITISH JOURNAL OF VENEREAL DISEASES}

rehabilitation. Even if one is sceptical about the possibility of changing a personality which is based on an inherited mental subnormality and aggravated by a faulty environment during childhood, such an attempt should be made for humanitarian reasons alone. In the U.S.S.R. highly satisfactory results were achieved in the nineteen-twenties in the so-called prophylactoria which were set up to deal with the large number of prostitutes-an aftermath of war and revolution (Scott).

Fortunately, at each venereal diseases clinic a large number of patients can be seen who, once having overcome (with the help of the staff of the clinic) the psychological shock caused by the diagnosis, present no further special problem. It is to be hoped that, with the raising of the general standard of education, the number of these patients will increase relatively. It is the patient of the uncooperative type who presents difficulties. Legislative measures alone have so far not been very successful. It might be possible, by studying the social and psychological factors which produce this type, to find another approach to the problem.

I wish to thank Col. L. W. Harrison, of the Ministry of Health, for his advice, Dr. F. Hall, County Medical Officer of Health for Lancashire, for permission to publish these statistics, and Miss M. Armitage for her most valuable work as Venereal Diseases Almoner.

\section{REFERENCES}

Abel, Theodora M., and Kinder, Elaine F. (1942) The Subnormal Adolescent Girl. Columbia University Press, New York.

Burn, J. L. (1941) Lancet, 2, 655.

Fessler, A. (1936) ${ }^{1}$ Wien. med. Wschr., 86, 1273. - $(1937)^{2}$ ibid., 87, 95.

Gordon, J. E. (1944) Lancet, 2, 711.

Hallgren, R. J. M. (1944) Publ. Hlth. Lond., 57, 96.

Harrison, L. W. (1941) ${ }^{1}$ Brit. J. vener. Dis., 17, 249. - (1945) $)^{2}$ ibid., 21, 21.

Jameson, W. (1943) Brit. J. vener. Dis., 19, 34.

Laird, S. M. (1942) ${ }^{1}$ Brit. J. vener. Dis., 18, 84. - $(1943)^{2}$ Venereal Disease in Britain. Penguin Books, London.

Manchée, Dorothy M. (1938) Social Service in the Clinic for Venereal Diseases. 1st ed. Baillière, Tindall and Cox, London.

Medical Advisory Committee for Scotland (1944) Report on Venereal Diseases. Cmd. 6518. H.M. Stationery Office, London.

Medical Society for the Study of Venereal Diseases (papers and discussion) (1945) Brit. J. vener. Dis., 21, 12-26.

Ministry of Health (1939) ${ }^{1}$ Report for 1938. H.M. Stationery Office, London. - (1943) $)^{2}$ Circular 2834. H.M. Stationery Office, London.

Osler, W. (1917) Brit. med. J., 1, 694.

Rachlin, H. L. (1944) J. vener. Dis. Inform., 25, 265.

Ross, A. O. F. (1944) Publ. Hlth. Lond., 57, 135.

Royal Commission on Venereal Diseases (1916) Final Report. H.M. Stationery Office, London.

Scott, J. A. (1945) Brit. J. vener. Dis., 21, 2.

Shiels, D. (1945) Practitioner, 154, 273.

Tyneside Experimental Scheme in Venereal Disease Control (1945) Brit. J. vener. Dis., 21, 26.

Wittkower, E. D., and Cowan, J. (1944) Psychosomatic Med., 6, 287.

White, E. L. (1922) Med. Offr., 27, 113.

\footnotetext{
Venereal diseases statistics for $1944-1945$

On page 10 of the Summary Report of the Ministry of Health for the year ended 31st March, 1945 (Cmd. 6710, H.M. Stationery Office, London) some figures relating to the incidence of venereal disease in the United Kingdom in the year 1944 are given. The returns on which they are based are those from treatment centres, and relate to early syphilis and to gonorrhoea, probably covering the great majority of cases of the former disease, whereas a larger number of patients with gonorrhoea may have been dealt with in private practice: The syphillis figures, although smaller than for 1943, are still much over 100 per cent larger than those for 1939, and whereas there was some reduction of incidence among men, among women it was still on the increase. Reference is made to penicillin treatment, and also to the examination of contacts and to the educational campaign.
} 